\title{
ANNE-AURORE INQUIMBERT, Stendhal secret. To the happy few
}

\section{Michel Arrous}

\section{(2) OpenEdition}

\section{Journals}

\section{Édition électronique}

URL : https://journals.openedition.org/studifrancesi/22791

DOI : 10.4000/studifrancesi.22791

ISSN : 2427-5856

\section{Éditeur}

Rosenberg \& Sellier

\section{Édition imprimée}

Date de publication : 1 avril 2020

Pagination : 184-185

ISSN : 0039-2944

\section{Référence électronique}

Michel Arrous, « Anne-AURore Inquimbert, Stendhal secret. To the happy few », Studi Francesi [En ligne], 190 (LXIV | I) | 2020, mis en ligne le 01 mai 2020, consulté le 03 août 2021. URL : http://

journals.openedition.org/studifrancesi/22791; DOI : https://doi.org/10.4000/studifrancesi.22791

Ce document a été généré automatiquement le 3 août 2021.

\section{(2) $\odot \Theta \Theta$}

Studi Francesi è distribuita con Licenza Creative Commons Attribuzione - Non commerciale - Non opere derivate 4.0 Internazionale. 


\title{
ANNE-AURORE INQUIMBERT, Stendhal secret. To the happy few
}

\author{
Michel Arrous
}

\section{RÉFÉRENCE}

ANNE-AURORE INQUIMBERT, Stendhal secret. To the happy few, Paris, L'Harmattan, 2018, $227 \mathrm{pp}$.

1 Spécialiste d'histoire militaire, mais aussi Grenobloise qui, de son propre aveu, ignora longtemps l'œuvre de Stendhal, A.-A. Inquimbert a pris le risque d'emprunter une piste qui l'a conduite, à l'aide d'une copieuse bibliographie, à explorer et décrypter dans Armance, Le Rouge et le Noir et La Chartreuse de Parme - Lucien Leuwen est laissé de côté ce qu'elle appelle leur "versant secret», sans rapport avec l'éthique du secret analysée par G. Durand, autrement dit un Stendhal occulte, à la fois maçonnique et alchimique, qui raconterait l'histoire d'une initiation spirituelle. Et cela au prétexte que Beyle fut reçu apprenti maçon, le 3 août 1806, à la très officielle, politique et mondaine loge Sainte-Caroline du Grand Orient de France. On peut donc fortement douter de l'engagement maçonnique de Stendhal, surtout si on le compare à celui de Destutt de Tracy!

2 La démarche n'est pas nouvelle: $\mathrm{Ch}$. W. Thompson avait déjà repéré un «système ésotérique» dans l'œuvre romanesque, Ch. Weiand avait vu dans la fréquence du chiffre trois «une trinité énigmatique et peut-être mythique»; quant à la symbolique maçonnique, elle a fait l'objet des recherches érudites d'A. Collet, D. Diefenbach ou L. Bauer, pour ne rien dire de celles tout aussi spéculatives de P.A. Bergher. À l'aide d'exemples discutables - le rôle des croyances ou des superstitions des personnages est confondu avec le discours du narrateur - sinon faux, d'approximations hardies ou de vagues allusions, de détails sortis de leur contexte, d'interprétations incomplètes (à propos des procédés oraculaires), l'auteur veut prouver, c'est une gageure, qu'on a affaire à des romans initiatiques dont la dimension ésotérique saute aux yeux, du moins 
pour ceux qui réfléchissent «avec les yeux de la tête», comme disait Napoléon. On a droit au déchiffrement des trois romans selon le code maçonnique, sans exclure la numérologie (les études de J.-L. Douchin et de N. Baverez, "Stendhal Club", n¹03, 1964 et $n^{\circ} 120,1968$, ont été omises), alors que, même si le chiffre trois est récurrent dans la Chartreuse, la logique numérique de Stendhal est souvent défaillante. On en dira autant de la croyance en la symbolique des nombres qui caractérise très justement Fabrice (les 70 cierges de Saint-Pétrone où les «références au triangle et au chiffre sept [...] renvoient directement à la franc-maçonnerie»); une croyance qu'il est difficile de prouver chez Stendhal (pourquoi, par exemple, n'avoir pas fait un sort au 15 mai 1796?). Invoquer l'exégèse biblique passe encore, mais recourir à la kabbale hébraïque, était-ce indispensable, sans oublier le culte d'Isis (cette fois on retrouve le langage mythologique et ce qu'on a appelé l'«inspiration mystique» de l'auteur de la Chartreuse)? Curieusement, dans le cas de la Chartreuse, la présence du vocabulaire de la spiritualité dans la relation amoureuse passe à la trappe. Mis systématiquement en œuvre dans la première partie de l'ouvrage («L'art du roman double», pp. 19-147), pour le Rouge où se lirait la première étape du Grand CEuvre alchimique, et plus encore pour la Chartreuse où l'on retrouverait les trois degrés de l'initiation maçonnique, ce type de lecture est presque abandonné dans la seconde («Aspects de l'humanisme dans l'œuvre de Stendhal», pp. 151-207); fort heureusement car on finirait par croire que Fabrice est franc-maçon sans le savoir!

L'auteur fait preuve de plus d'objectivité pour montrer que dans l'œuvre autobiographique, sous le signe du nosce te ipsum, se développe une recherche de l'intériorité - H.-F. Imbert y voyait ce qu'il a appelé l'«ésotérisme beyliste» - qui va s'approfondissant dans les années 1835-1836. Mais, à vrai dire, est-on en présence d'un second sens auquel seuls accèderaient quelques heureux? Tout lecteur du Journal ou de la Vie de Henry Brulard, sans nécessairement compter au nombre des stendhaliens experts (plus d'une fois rappelés à l'ordre), peut mesurer l'effort de Stendhal dans la connaissance de soi et dans la volonté d'être soi-même. C'est d'ailleurs ce que mettent en évidence, à partir de la Filosofia nova et des lettres à Pauline, "“Connais-toi toimême": le laboratoire Henri Beyle», et «La chasse au bonheur». Ces deux chapitres assez bien venus sur la «doctrine intérieure», sans doute parce que le lien avec l'argument initial se distend, témoignent d'une lecture attentive de la quête de la vérité chez cet «honnête homme» que fut Stendhal, une quête poursuivie dans ses romans. 